\title{
EFFECT OF SCANDIUM-CONTAINING WIRE ON STRUCTURE AND PROPERTIES OF JOINTS OF ALUMINUM-LITHIUM ALLOYS PRODUCED BY ARGON-ARC WELDING
}

\author{
L.I. MARKASHOVA, O.S. KUSHNARYOVA and I.I. ALEKSEENKO \\ E.O. Paton Electric Welding Institute, NASU \\ 11 Bozhenko Str., 03680, Kiev, Ukraine. E-mail: office@paton.kiev.ua
}

\begin{abstract}
Relevance of application of complex experimental-analytical approach for estimation of the most important mechanical properties is shown by the example of welded joints of complexly alloyed aluminum-lithium alloy 1460 of $\mathrm{Al}-\mathrm{Cu}-\mathrm{Li}$ system, produced by argon-arc welding using filler wires Sv-1201 and Sv-1201 + $+0.5 \%$ Sc. The estimation of service properties (strength, ductility, crack resistance) of the welded joints was carried out considering specific contribution of structural factors (chemical composition, grain, subgrain and dislocation structure as well as size and volume fraction of forming phase precipitates). Effect of each of specific structural-phase parameters on mechanical properties of the welded joints, their change under influence of postweld heat treatment and external loads as well as role of structural-phase condition for concentration and mechanism of relaxation of the internal stresses at metal alloying with scandium were determined. 12 Ref., 5 Figures.
\end{abstract}

Keywords: aluminum alloys, welded metal, scan dium, heat treatment, structural-phase condition, phase precipitates, substructure, dislocation density, service properties, crack resistance

Approach to optimizing and correction of structure $\leftrightarrow$ property relationship with technology of welding and postweld heat treatment (PWHT), which should provide sufficient level of welded joint service properties [1], is highly relevant considering rising necessity in materials for manufacture of structures, operating under complex service conditions, that to significant extent refers to airspace equipment. Superlight Al-Li alloys can be referred to such materials with special properties. They have sufficient level of specific strength, ductility and crack resistance under complex service conditions as well as manufacturability at cryogenic temperatures [2, 3].

In this case it should be noted that some important properties of the complexly alloyed $\mathrm{Al}-$ $\mathrm{Li}$ alloys (strength characteristics, fracture toughness, crack resistance, resistance to external loads, including dynamic ones) rapidly change in process of manufacture of the structures and at their operation, that is mainly related with special structural-phase transformations in process of different technological operations as well as under effect of welding conditions [3]. Changes of the mechanical properties of similar types of alloys are also representative from this point of view. They are caused by heat treatment

(c) L.I. MARKASHOVA, O.S. KUSHNARYOVA and I.I. ALEKSEENKO, 2014 and related not only with effect of chemical composition and main structural factors, but also with changing of their phase composition [4].

Estimation of effect of the different special structure-phase constituents on change of the most important for service conditions mechanical properties, namely strength indeces and ductility of the welded joints, is relevant considering complexity of the structure-phase condition of these materials and, in particular, processes of phase formation under various conditions of thermodeformation influence. It is also interesting to study an effect of structural and phase characteristics of the welded joints on process of accumulation of the internal stresses and possibility of their plastic relaxation, that indicates crack resistance of material being deformed, in particular, under complex aerodynamic conditions.

Solving of such problems, first of all, require the most complete experimental database, reflecting real structure-phase composition of examined material, which is formed using technological modes of argon-arc welding, changes of this state under conditions of PWHT and external loads.

The basic experimental information about structure-phase condition of the weld metal of aluminum alloy 1460 welded joints $\left(\mathrm{Al}-3 \% \mathrm{Cu}^{-}\right.$ $2 \% \mathrm{Li}-0.08 \% \mathrm{Sc}$ ), produced using filler wires $\mathrm{Sv}-1201(\mathrm{Al}-6.5 \% \mathrm{Cu}-0.25 \% \mathrm{Zr}-0.3 \% \mathrm{Mn})$ with scandium $(0.5 \%)$ and without it, was received during the following stages of examina- 

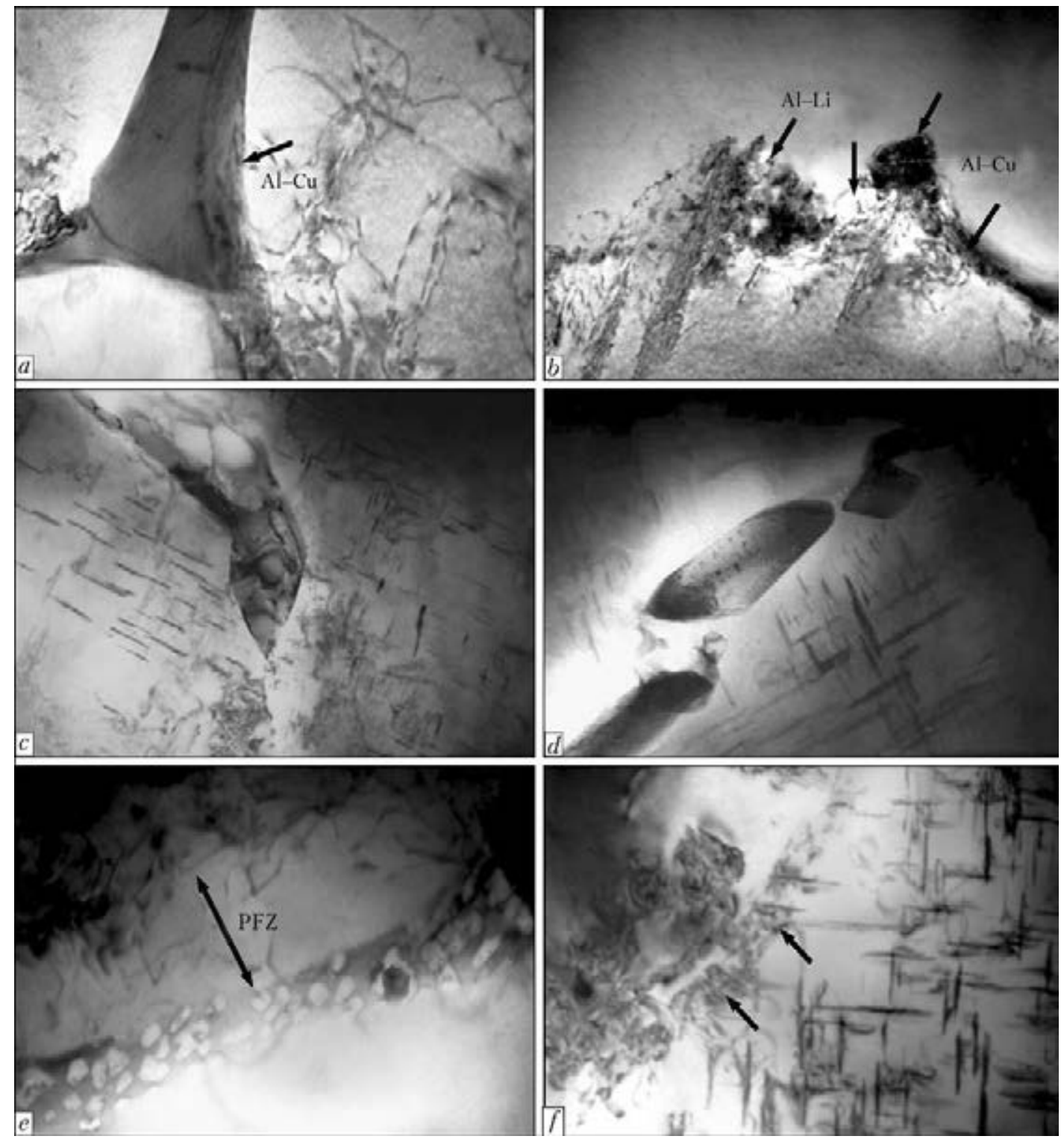

Figure 1. Microstructure $(\times 30,000)$ of weld metal of Al-Lu alloy 1460 welded joints produced using filler wire Sv-1201 $(a, c, e)$ and $\mathrm{Sv}-1201+0.5 \% \mathrm{Sc}(b, d, f): a, b$ - after welding; $c, d$ - after annealing; $e-$ near-boundary PFZ; $f-$ density of distribution of phases and dislocations in near-boundary PFZ

tion: 1 - immediately after argon-arc welding; $2-$ PWHT (aging at $T=150{ }^{\circ} \mathrm{C}$ during $22 \mathrm{~h}$ and annealing at $T=350{ }^{\circ} \mathrm{C}$ for $\left.1 \mathrm{~h}\right) ; 3-$ external dynamic loading of produced welded joints. Complex methodological approach, including optical, analytical scanning microscopy (Philips SEM 515, Holland) as well as microdiffraction transmission electron microscopy (JEOL JEM-200CX, Japan) with accelerating voltage $200 \mathrm{kV}$, was used for the examination at different structural levels.

The examination of structure-phase changes in weld metal of the joints after welding and PWHT depending on scandium alloying found [5-7] that application of Sv-1201 wire without scandium immediately after welding forms grain structure, differing by special structure-phase condition inside the grains (Guinier-Preston zones, $\mathrm{Al}_{3} \mathrm{Li}, \mathrm{Al}_{3} \mathrm{Zr}$ ) and intergrain boundary (IGB). More exactly it is caused by presence in IGB of the eutectics, which are complex on phase composition, solid, elongated and consist mainly from $\mathrm{Al}-\mathrm{Li}$ and $\mathrm{Al}-\mathrm{Cu}$ phases, as well as formation of special near-boundary zones free from precipitates (PFZ), which as a rule provokes decrease of mechanical properties of the welded joints (Figure 1, $a, d$ ).

The following peculiarities of structural changes are observed after welding using of Sccontaining wire Sv-1201.

First of all, size of the weld crystalline particles are almost 3 times lower than in use of filler without scandium (Figure $1, b)$. PWHT $\left(350{ }^{\circ} \mathrm{C}\right.$, $1 \mathrm{~h}$ ) results in refining of the substructure (blocks, subgrains). This promotes the more active redistribution of the chemical elements, that 


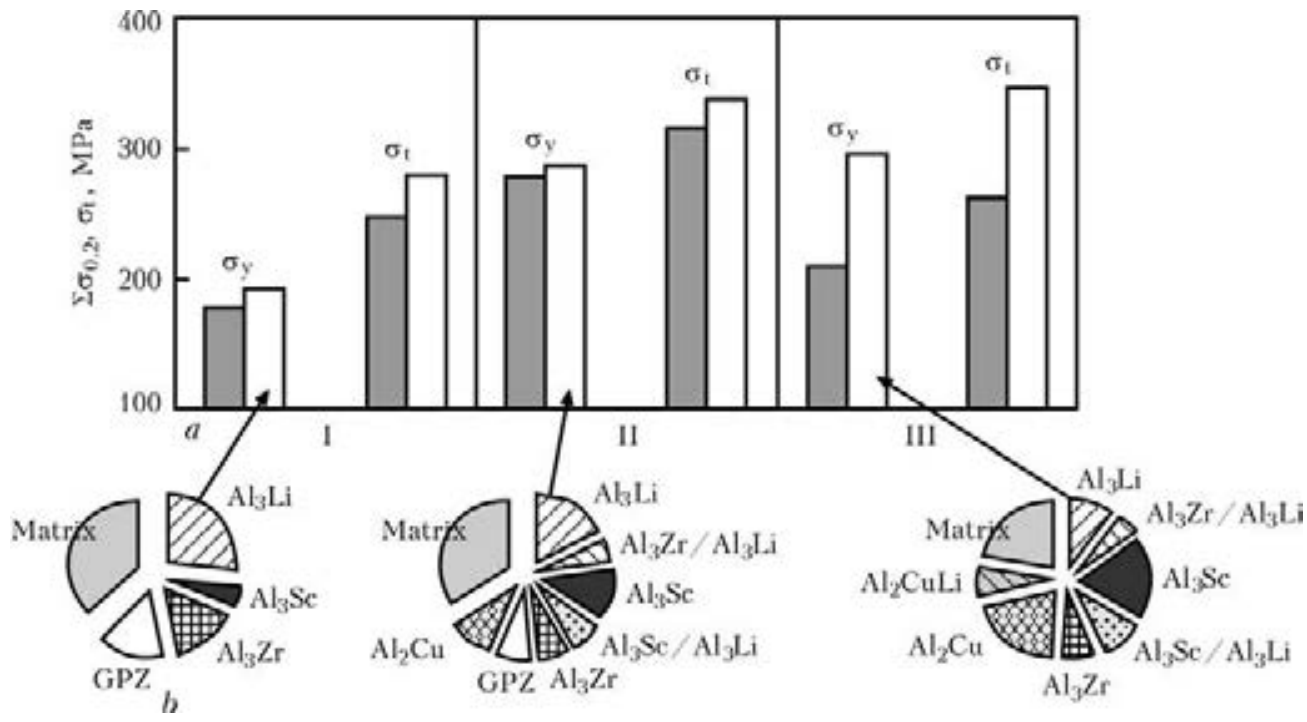

Figure 2. Histogram of differential contribution of separate structural parameters in integral change of yield strength and tensile strength of welded joint of alloy 1460, produced using filler wire Sv-1201 (dark columns) and Sv-1201 + $+0.5 \% \mathrm{Sc}$ (white) $(a)$, and sector diagrams of volume fractions of phases in use of Sv-1201 + $0.5 \%$ Sc $(b)$ : I - after welding; II - aging $\left(150{ }^{\circ} \mathrm{C}, 22 \mathrm{~h}\right)$; III - annealing $\left(350{ }^{\circ} \mathrm{C}, 1 \mathrm{~h}\right)$

is caused by processes of solid solution decomposition and further formation of new phases (Figure 1,c). Additional scandium alloying also provides for rise of the general dislocation density and activation of the processes of their redistribution (Figure 1, $d$ ).

Secondly, heat treatment at scandium alloying promotes change of IGB structure, namely density of the grain boundary eutectics becomes somewhat weaker (loose) and volume fraction of lithium phases along IGB significantly reduces. The Sc-containing phase precipitates forming during heat treatment fill up IGB area and make them significantly narrower, that, in turn, promotes for leveling of negative effect of this zone, clearly observed in the case of scandium absence (Figure 1, $f)$. As for the grain boundary eutectic developments, then eutectic in the weld metal with additional scandium alloying «breaks up» during heat treatment and decomposes on separate individual phase developments (Figure 1, $d$ ).

Experimental results, received at different structural levels from marco- (grain) to micro(dislocation) allowed carrying out the analytical estimation for determination of differential $(\Delta \sigma)$ contribution of the different structure-phase parameters in change of integral $\left(\Sigma \sigma_{\mathrm{y}}\right)$ values of the mechanical characteristics and, first of all, strength as well as ductility and crack resistance. At that, the estimation of total value of increment of yield strength $\Sigma \sigma_{\mathrm{y}}$ for the weld metal without scandium and with scandium was carried out on analytical dependencies of Hall-Petch, Orowan etc. [8-10] considering resistance of metal lattice to movement of free dislocations (lattice friction stress $\Delta \sigma_{0}$ ), chemical composition (solid solution strengthening $\left.\Delta \sigma_{\mathrm{s} . \mathrm{S}}\right)$, grain $\left(\Delta \sigma_{\mathrm{g}}\right)$ and subgrain $\left(\Delta \sigma_{\mathrm{s}}\right)$ strengthen- ing as well as real dislocation density (dislocation strengthening $\Delta \sigma_{\mathrm{d}}$ ) and phase precipitates (dispersion strengthening $\Delta \sigma_{\mathrm{d} . \mathrm{s}}$ ).

The estimation showed that integral value of the weld metal strength and actual contribution of different structural factors change depending on technological modes (welding, heat treatment) as well as alloying. Increase of strength characteristics $\left(\Sigma \sigma_{\mathrm{y}}\right)$ approximately by $16 \mathrm{MPa}$ $(8 \%)$ immediately after welding, by $8 \mathrm{MPa}$ (3\%) after aging $\left(150{ }^{\circ} \mathrm{C}, 22 \mathrm{~h}\right)$ and by $86 \mathrm{MPa}$ (29\%) after annealing $\left(350{ }^{\circ} \mathrm{C}, 1 \mathrm{~h}\right)$ is observed in Sc-containing weld in comparison with weld without scandium. In the latter case, the phase developments have the maximum effect in strengthening (around $31 \%$ ) and dislocation density has the lowest one (almost to $7 \%$ ). Figure 2, $a$ provides for the information on contribution of other structural factors in strengthening for the examined weld compositions at indicated modes. It should be noted that $\mathrm{Al}_{2} \mathrm{Co}(20 \%)$ and $\mathrm{Al}_{3} \mathrm{Sc}(20 \%)$ precipitates (Figure 2, $b$ ) have significant contribution in the level of dispersion strengthening of the weld metal. They are the main strengthening phases. Contribution of the phases of other type in dispersion strengthening is not so significant and makes 5-10\%. Given estimation of changes of the yield strength, carried out with consideration of structures being really formed in the weld metal, allows also estimating the ultimate weld strength $\left(\sigma_{t}\right)$ using dependence [10]

$$
\frac{\sigma_{\mathrm{y}}}{\sigma_{\mathrm{t}}}=\left(\frac{\sigma_{\mathrm{y}}}{\aleph}\right)^{2}(1+m) \sqrt{1+\frac{2}{1+m}\left(\frac{\aleph}{\sigma_{\mathrm{t}}}\right)^{2}},
$$

where $m=0.3$; $\aleph$ is the coefficient of deformation strengthening. 
$K_{1 c}, \mathrm{MPa} \cdot \mathrm{m}^{1 / 2}$

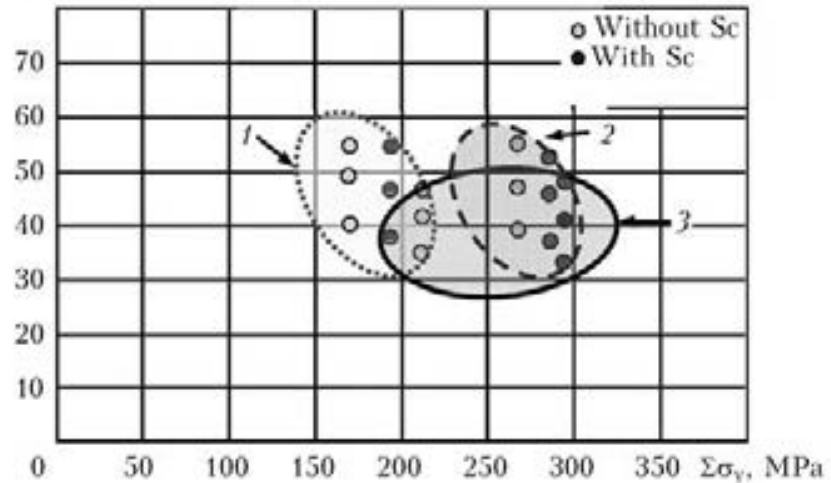

Figure 3. Diagram of change of calculation strength and fracture toughness for weld metal of alloy 1460 welded joint after welding (1), aging $\left(150{ }^{\circ} \mathrm{C}, 22 \mathrm{~h}\right)(2)$ and annealing $\left(350{ }^{\circ} \mathrm{C}, 1 \mathrm{~h}\right)(3)$

Effect of the structural factors on change of parameters of weld metal fracture toughness $\left(K_{1 C}\right)$ (Figure 3 ) was also determined. $K_{1 C}$ values were determined on Krafft dependence [11] $K_{1 C}=\left(2 E \sigma_{\mathrm{y}} \delta_{\mathrm{c}}\right)^{1 / 2}$ (where $E$ is the Young's modulus; $\sigma_{\mathrm{y}}$ is the calculation strengthening; $\delta_{\mathrm{c}}$ is the critical crack opening, received on data of fractographic analysis of fractures considering size of facets (or pits on fracture surface)).

It was determined that scandium alloying provides for reduction of $K_{1 C}$ parameter on average
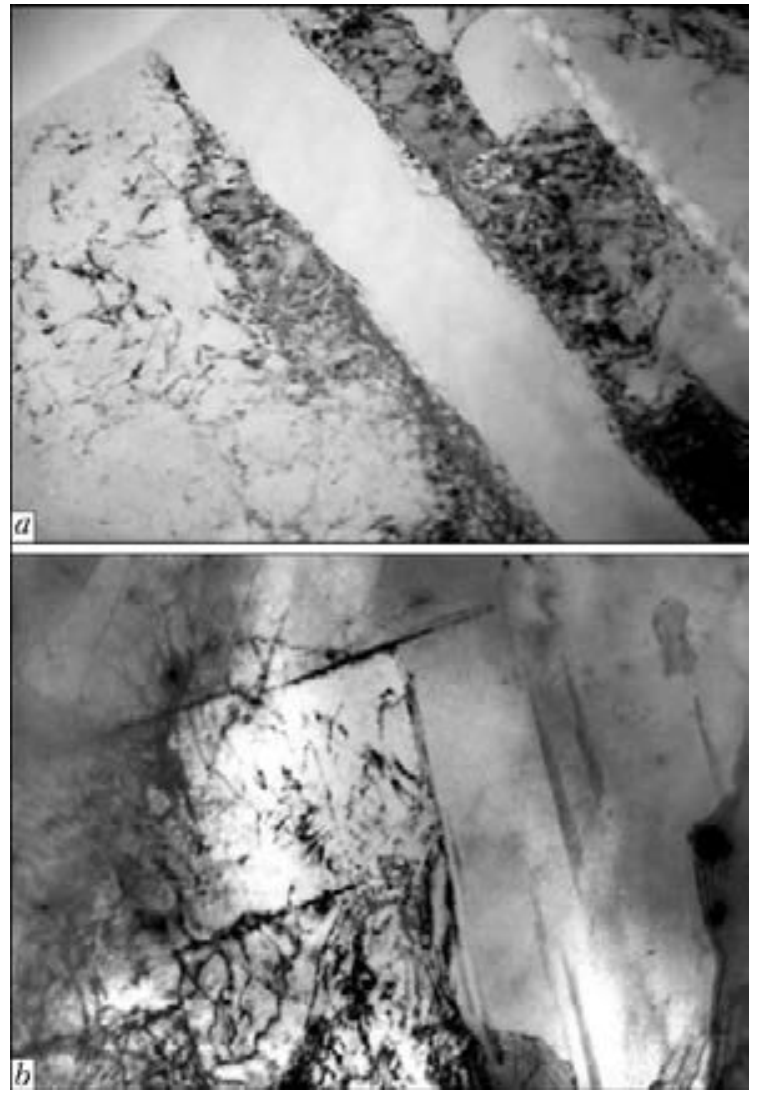

Figure 4. Fine structure $(\times 37,000)$ of annealed $\left(350{ }^{\circ} \mathrm{C}\right.$, $1 \mathrm{~h})$ weld metal of alloy 1460 welded joint under conditions of dynamic loading: $a-$ weld without scandium; $b-$ Sc-containing weld by $5 \%$ and makes $35-43 \mathrm{MPa} \cdot \mathrm{m}^{1 / 2}$ (Figure 3 ) together with rise of yield strength of the weld metal immediately after welding. The same situation takes place after aging, namely, on average $6 \%$ reduction of $K_{1 C}$ to $32-41 \mathrm{MPa} \cdot \mathrm{m}^{1 / 2}$. Annealing has lager effect on change of $K_{1 C}$ parameter of the weld metal without scandium, i.e. $25 \%$ reduction of strength is observed in comparison with $K_{1 C}$ after welding. Scandium alloying promotes virtually no change in fracture toughness, and provokes more strength increase, that indicates the optimum combination of resource characteristics of such welded joints (see Figures 2 and 3 ).

Examination of the weld metal fine structure after annealing $\left(350{ }^{\circ} \mathrm{C}, 1 \mathrm{~h}\right)$, which particularly demonstrates a role of scandium and further dynamic loading, shows non-uniform distribution of the dislocations with clear deformation localizing in the examined zone without scandium, and the deformed metal receives respectively unstable structural condition. The latter is observed in an avalanche-like barrier-free metal flow, that is indicated by strong slip systems and shear bands (Figure 4, $a$ ). At that, significant non-uniformity is observed in the distribution of dislocation density along the shear bands, where $\rho$ $\sim 1.10^{8}-2 \cdot 10^{9} \mathrm{~cm}^{-2}$ inside the shear bands, and $\rho \sim 8 \cdot 10^{10}-2 \cdot 10^{11} \mathrm{~cm}^{-2}$ directly along the band boundary, that results in formation of steep gradients of the local internal stresses $\left(\Delta \tau_{1 \text { in }}\right)$.

Estimation of $\tau_{1 \text {.in }}$ considering dislocation density [12] determined that the shear boundaries represent themselves the elongated local stress concentrators, where $\tau_{1 \text { in }}=600-1500 \mathrm{MPa}$ ( $G /(0.45-0.18)$, where $G$ is the shear modulus). In turn, values of $\tau_{\text {l.in }}$ in internal volumes of the shear bands rapidly decrease up to 5-15 $\mathrm{MPa}$ (approximately 2 orders) (Figure $5, a$ ). As a result, steep $\left(\Delta \tau_{1 . \text { in }}=590-1480 \mathrm{MPa}\right)$ elongated gradient of the local internal stresses, being the reason of crack formation and, consequently, reduction of the properties, is developed in the weld metal without scandium under conditions of dynamic loading

Structure of another nature is observed in the weld metal in the case of scandium alloying under similar conditions of dynamic loading. It is characterized by more uniform dislocation distribution without significant gradients as well as general refinement (fragmentation) (see Figure 4, $b)$. At that, phase precipitates of special type with Sc-containing constituents (Figure 5, b) provide for stable blocking of the appearing strong slip systems. These phases promote structure fragmentation and, respectively, more uni- 

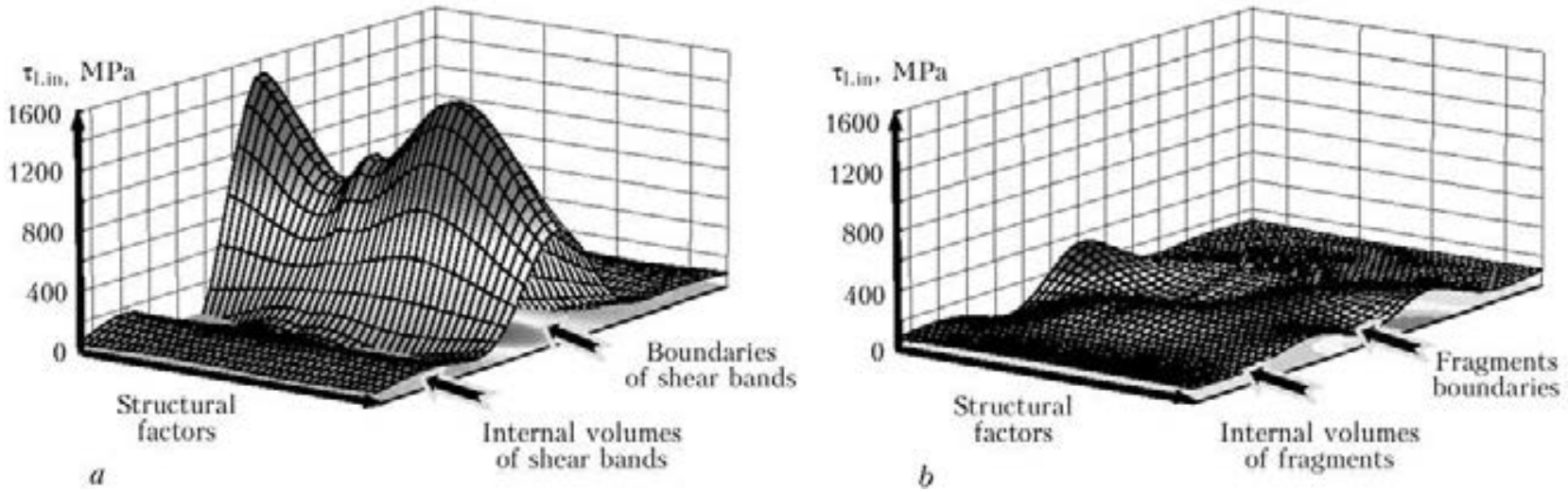

Figure 5. Distribution of local internal stresses in weld metal, produced using filler wire Sv-1201 (a) and Sv-1201 + $+0.5 \%$ Sc $(b)$, after heat treatment $\left(350{ }^{\circ} \mathrm{C}, 1 \mathrm{~h}\right)$ and external dynamic loading

form distribution of internal stresses in the weld metal. Formation of the structures of similar type rises possibility of plastic relaxation of the increasing internal stresses due to connection of additional rotation mechanisms to the dislocation ones, that is supported by tough nature of the welded joint fracture.

\section{Conclusions}

1. Scandium alloying of weld metal in comparison with its condition without scandium for all studied modes of welding and heat treatment results in the dispersion of phases, grain and subgrain structure, rise of dislocation density and their uniform distribution, activation of processes of phase formation in the internal grain volumes and reduction of volume fraction of grain boundary eutectics.

2. Analytical estimations of differential contribution of the various structural-phase parameters in the change of strength properties $\left(\sigma_{\mathrm{v}}, \sigma_{\mathrm{t}}\right)$, ductility $\left(K_{1 C}\right)$ and crack resistance of the examined welded joints showed that scandium alloying promoted for rise of general value of yield strength $\Sigma \sigma_{\mathrm{y}}$ of the welded joints, in particular, after annealing. Phase developments make the largest contribution in strengthening $(\Delta \sigma)$, and dislocation density has the lowest one.

3. Scandium alloying promotes the more uniform distribution of rising local internal stresses, fragmentation of strong shear bands, forming in the weld under conditions of dynamic loading, that improves the welded joint crack resistance and, respectively, increase of relaxation possibility of the weld due to connection of additional rotation mechanisms of plastic relaxation to the dislocation ones.

1. Markashova, L.I., Grigorenko, G.M., Arsenyuk, V.V. et al. (2002) Criterion for evaluation of mechanical properties of dissimilar material joints. In: Proc. of Int. Conf. on Mathematical Modelling and Information Technologies in Welding and Related Processes (16-20 Sept. 2002, Katsiveli, Crimea, Ukraine). Kiev: PWI, 107-113.

2. Fridlyander, I.N., Chuistov, K.V., Berezina, A.L. et al. (1992) Aluminium-lithium alloys. Structure and properties. Kiev: Naukova Dumka.

3. Davydov, V.G., Elagin, V.I., Zakharov, V.V. (2001) Studies of VILS in field of increase in quality and manufacturability of aluminium alloy semi-products. Tekhnologiya Lyog. Splavov, 5/6, 6-16.

4. Zakharov, V.V. (2003) Some problems in application of aluminium-lithium alloys. Metallovedenie $i$ Termich. Obrab. Metallov, 2, 8-14.

5. Markashova, L.I., Grigorenko, G.M., Ishchenko, A.Ya. et al. (2006) Effect of scandium additions on fine structure of weld metal in aluminium alloy 1460 welded joints. The Paton Welding J., 2, 20-25.

6. Markashova, L.I., Grigorenko, G.M., Lozovskaya, A.V. et al. (2006) Effect of scandium additions on structure-phase state of weld metal in aluminium alloy joints after heat treatment. Ibid., 6, 7-11.

7. Markashova, L.I., Kushnaryova, O.S. (2012) Welded joints of complexly alloyed aluminium-lithium alloys, structure and operational properties. In: Transact. on Building, Materials Science, Machine-Building. Issue 64. Dnepropetrovsk: PGASA, 75-80.

8. Konrad, G. (1973) Model of deformation strengthening for explication of grain size effect on metal flow stress. In: Extrafine grain in metals. Ed. by L.K. Gordienko. Moscow: Metallurgiya, 206-219.

9. Kelly, A., Nickolson, R. (1966) Dispersion hardening. Moscow: Metallurgiya.

10. Goldshtejn, M.I., Litvinov, V.S., Bronfin, B.M. (1986) Physics of metals of high-strength alloys. Moscow: Metallurgiya.

11. Romaniv, O.N. (1979) Fracture toughness of structural steels. Moscow: Metallurgiya.

12. Koneva, N.A., Lychagin, D.V., Teplyakova, L.A. et al. (1986) Theoretical and experimental examination of disclinations. Leningrad: LFTI, 116-126. 